\title{
Health literacy and use of healthcare services among community-dwelling older adults living with chronic conditions
}

\author{
Isabelle Dufour*1,2, Anais Lacasse ${ }^{3}$, Maud-Christine Chouinard ${ }^{1}$, Yohann Chiu ${ }^{2}$, Sarah Lafontaine ${ }^{2}$ \\ ${ }^{1}$ Département des sciences de la santé, Université du Québec à Chicoutimi, Quebec, Canada \\ ${ }^{2}$ Faculté de médecine et des sciences de la santé, Université de Sherbrooke, Quebec, Canada \\ ${ }^{3}$ Département des sciences de la santé, Université du Québec en Abitibi-Témiscamingue, Quebec, Canada
}

Received: December 19, 2018

Accepted: March 18, 2019

Online Published: March 25, 2019

DOI: $10.5430 /$ cns.v7n2p79

URL: https://doi.org/10.5430/cns.v7n2p79

\begin{abstract}
Objective: Only $12 \%$ of the Canadian older adults have adequate health literacy (HL) to understand and handle health information sufficiently. A descriptive correlation study was conducted to describe HL and to examine its relationship with healthcare services use among community-dwelling older adults living with chronic conditions in a distant region of Quebec, Canada.

Methods: Data were collected through self-report instruments including the Health Literacy Questionnaire (HLQ), which assesses HL on nine dimensions.

Results: Based on health characteristics of the nine HLQ dimensions, the results showed significant differences between subgroups of participants as well as a negative association between the HLQ dimension Appraisal of Health Information and the number of consultations with healthcare professionals (incidence rate ratio: $0.66 ; p=.027$ ).

Conclusions: The results highlight the need to improve older adults HL, in order to improve their health status and use of healthcare services.
\end{abstract}

Key Words: Health literacy, Aged, Community dwelling, Healthcare services, Health Literacy Questionnaire, Chronic diseases

\section{INTRODUCTION}

The reversal of the age pyramid due to population aging could have a number of significant consequences. The costs associated with healthcare service use are expected to increase and so is the number of older adults living at home and having to care for themselves. ${ }^{[1]}$ In order to sufficiently and adequately manage their own health, home-dwelling older adults need to manage information about their medical treatments and make appropriate lifestyle choices. ${ }^{[2,3]}$ This corresponds to health literacy (HL). Although several definitions are reported, HL is defined by consensus as the individual ability to obtain, manage and understand health information in order to make appropriate health choices. ${ }^{[3,4]}$ A systematic review by Sorensen et al. ${ }^{[4]}$ deepened this definition by stating that HL entails the capacity of people to "make judgments and take decisions in everyday life concerning healthcare, disease prevention and health promotion to maintain or improve quality of life during the life course".

According to empirical research, HL can influence a person's quality of life, self-management of chronic health conditions

\footnotetext{
*Correspondence: Isabelle Dufour, RN, MSc; Email: isabelle2_dufour@uqac.ca; Address: Département des sciences de la santé, Université du Québec à Chicoutimi, 555 Boul. de 1'Université, Chicoutimi, Quebec, G7H 2B1, Canada.
} 
and reduce reliance on the healthcare system. ${ }^{[1,5,6]}$ Low HL prevalence is higher among older adults. A large Canadian study found that only $12 \%$ of individuals aged 65 and older assessed had an adequate level of HL. ${ }^{[3]}$ A systematic review by Berkman et al. ${ }^{[7]}$ showed that the consequences of low HL are numerous: reduced overall health, increased mortality, increased use of emergency services and hospitalizations, low use of preventive services and suboptimal compliance with pharmaceutical treatments. Older adults with inadequate HL can also tend to have a higher number of chronic conditions, as they have lower health knowledge and pay less attention to prevention. ${ }^{[8]}$

HL concept extends beyond individuals. It involves interactions between individuals and the healthcare system. The quality of these interactions can influence the patients' HL and the way they use healthcare services. ${ }^{[4]}$ Healthcare providers are directly part of these interactions, especially nurses, as they are often the main point of contact with patients. Thus, they should be made aware of their patients' HL issues and be informed on the factors influencing the use of healthcare services. Among other things, this could help them adjust their approach, including their education and communication skills, and develop interventions aiming to optimize health follow-up.

The relationship between HL and the use of emergency health services is well documented. ${ }^{[9]}$ However, our knowledge regarding the relationships between HL and other types of health services is more limited. ${ }^{[10]}$ This relationship should still be examined, as HL may influence healthcare use in different settings, such as primary care and preventive services. $^{[11]}$

HL among older adults is a significant issue, as they must manage higher levels of health information. Indeed, older adults report higher levels of chronic conditions in comparison with their younger peers. ${ }^{[8]}$ In this context, low HL may decrease the ability to participate in healthcare activities and may negatively impact personal health management. ${ }^{[5]}$ Furthermore, a lack of research on older adults HL in distant regions was noted. Socioeconomic status and supply of health care services tend to be lower in distant regions than in urban centres, influencing health service use. ${ }^{[12]}$ In the context where offer and orientation of services must be adapted to patients needs, it is critical to study HL related to the usage of services of elderly people at home. They represent a population with vulnerability factors such as comorbidities and who is expected to use a significant amount of healthcare services in the upcoming years. ${ }^{[8]}$ In this study, the objectives are twofold: 1) to describe HL among different subgroups of community-dwelling older adults with chronic conditions; 2) to explore the link between HL and consultations with healthcare professionals in this specific population.

\section{Methods}

\subsection{Study design and settings}

A cross-sectional study was conducted. ${ }^{[13]}$ Participants were recruited in the three larger districts of a remote region in Quebec, Canada: Saguenay-Lac-St-Jean, through two family medicine groups and three community pharmacies.

\subsection{Participant characteristics}

French-speaking community-dwelling individuals 65 and older of the Saguenay region, with at least one chronic condition were considered for inclusion. People with disabling cognitive disorders or an unstable health condition were excluded.

Between July and October of 2015, older adults were recruited using a convenience, non-probabilistic sampling method. In each targeted setting, collaborating physicians and nurses solicited patients who fit the study eligibility criteria at the time of a consultation.

\subsection{Variables}

The dependent variable was the total number of consultations with healthcare professionals. Face-to-face interviews were conducted by the main author and were approximately 40 minutes in length. They were conducted at the participants' homes. Self-report instruments assessed the respondents' HL, use of healthcare services, number of chronic conditions as well as sociodemographic status. Those are the independent variables and are defined below.

\subsubsection{Health literacy}

The participants completed the French version of the Health Literacy Questionnaire (HLQ). ${ }^{[14]}$ The HLQ is a 44-item instrument that assesses HL on 9 dimensions: 1) Feeling understood and supported by healthcare providers; 2) Having sufficient information to manage one's health; 3) Actively managing one's health; 4) Social support for health; 5) Appraisal of health information; 6) Ability to actively engage with healthcare providers; 7) Navigating the healthcare system; 8) Ability to find good health information; 9) Understand health information enough to know what to do. The first five dimensions were assessed using a 4-point Likert scale ranging from Strongly disagree to Strongly agree. Dimensions 6 to 9 used a 5-point Likert scale ranging from Always difficult to Always easy. The score of the 9 subscales of the HLQ were obtained by summing the items included in each dimension. The HLQ does not allow the calculation of a total score. It was still chosen amongst other instruments, 
because it assesses HL needs and challenges among populations and organizations regarding its different dimensions. ${ }^{[14]}$ The English and French versions of the HLQ showed good psychometric properties. ${ }^{[14,15]}$

\subsubsection{Use of healthcare services}

The Questionnaire on healthcare service use aimed to measure the utilization of different types of healthcare services over a 6-month period. ${ }^{[16]}$ These services included hospitalization and emergency services as well as the number of consultations with different types of healthcare professionals: family physician, ophthalmologist, dentist or orthodontist, specialist, pharmacist, nurse, chiropractor, physiotherapist, occupational therapist, social worker, psychologist, audiologist, nutritionist and kinesiologist.

\subsubsection{Chronic conditions}

The French version of the Disease Burden Morbidity Assessment (DBMA) was used to determine the participants' number and type of chronic conditions. This instrument measures the participants' medical conditions using a list of 22 conditions such as arterial hypertension, asthma, diabetes and cardiac disease. The psychometric properties of the French version of the instrument were judged similar to the original English version. ${ }^{[17]}$

\subsubsection{Sociodemographic data}

The participants' sociodemographic data were obtained using a standard questionnaire: ${ }^{[18]}$ sex, age category $(65-69,70-$ $74,75-79,80-84$, and 85 or more), birthplace (Quebec, other Canadian province, other country), marital status (married, separated, single, and widowed), education level (primary, secondary, post-secondary, university), and income level (0 to $19,000 \$, 20$ to $39,000 \$, 40$ to $59,000 \$$, and $60,000 \$$ and more).

\subsection{Ethical consideration}

The ethics approval for this study was obtained from the Ethics review board of the Centre Intégré Universitaire de Santé et de Services Sociaux du Saguenay-Lac-Saint-Jean.

\subsection{Statistical analysis}

There was no missing or incorrect data reported in the database. The targeted sample size was about 75 participants, allowing an $80 \%$ statistical power while respecting a significance level of .05. ${ }^{[19]}$

Firstly, the participants' characteristics were described, along with the main study variables. The differences between subgroups based on sociodemographic and health characteristics were tested, using Wilcoxon rank-sum test, Kruskal-Wallis test, Student's $t$-test and ANOVA, according to the distributions of HLQ scores. A significance level of .05 was used.
Secondly, we used Poisson regression (due to the nature of the dependent variable, i.e. count data) to determine the presence of an association between HL and the total number of consultations with healthcare professionals. ${ }^{[20]}$ The independent variables were first tested individually in simple regression models. The ones with a $p$-value $<.15$ were then integrated into the multiple regression model. The final model used a significance level of .05 and we reported incidence rate ratios (IRR) with the associated $95 \%$ confidence intervals (CI). IBM SPSS Statistics ${ }^{\circledR}$ version 21 was used for all data analysis.

\section{RESULTS}

\subsection{Description of the population}

Among the 85 older adults initially identified, all of them met the inclusion criteria and 69 of them agreed to participate. The overall characteristics of the sample are presented in Table 1.

The sample was composed of 30 males (43.48\%) and 39 females $(56.52 \%)$, with a mean age of 74 . Almost all of the participants had multimorbidity $(97.10 \%)$, with a mean of five different chronic conditions. Six (8.7\%) participants had an episode of hospitalization and $19(27.54 \%)$ consulted the emergency services in the six months prior to data collection. The mean number of consultations with a family physician in the sample was 1.70 , with a maximum of six consultations. The majority of the participants also consulted a specialist $(\mathrm{n}=38,55.07 \%$ ), for an average number of consultations of 1.19 and a maximum of seven. Pharmacists were the most often consulted healthcare professionals with $52(75.46 \%)$ participants using their services, ranging from 1 to 24 consultations. Also, 29 (42.03\%) participants received nursing services or follow-up consultations from different settings, with a mean of 1.91 and a maximum of 24 consultations. Furthermore, 31 (45\%) participants consulted an optometrist in the previous 6 months, while other types of healthcare professionals were consulted by less than $30 \%$ of the participants. The mean for the total number of consultations was $11.57(\mathrm{SD}=12.75)$ with a maximum of 74 consultations.

\subsection{Description of $\mathbf{H L}$}

Table 2 shows the $9 \mathrm{HL}$ dimensions for different subgroups of participants. The overall HL scores were high for all the subgroups. The highest scores were for the dimensions Feeling understood and supported by healthcare professional and Understanding health information well enough to know what to do. Statistically significant differences were found between subgroups defined by education level and the number of chronic conditions (see Table 2). Participants with a university education scored significantly higher on the di- 
mensions Actively managing my health and Ability to find good health information than those with lower levels of education. Finally, participants with three or more chronic conditions scored significantly higher than participants with two or less chronic conditions on the dimension Understand health information. The lowest scores were for the dimensions Appraisal of health information and Navigating the healthcare system.

Table 1. Characteristics of the study sample

\begin{tabular}{|c|c|}
\hline Characteristics & N (\%) \\
\hline \multicolumn{2}{|l|}{ Age range (in years) } \\
\hline $65-69$ & $23(33.33)$ \\
\hline $70-74$ & $18(26.09)$ \\
\hline $75-79$ & $10(14.49)$ \\
\hline $80-84$ & $11(15.94)$ \\
\hline 85 and + & $7(10.14)$ \\
\hline \multicolumn{2}{|l|}{ Education level } \\
\hline Primary & $17(24.64)$ \\
\hline Secondary & $22(31.88)$ \\
\hline Post-secondary & $18(26.09)$ \\
\hline University & 12 (17.39) \\
\hline \multicolumn{2}{|l|}{ Income level (CAN \$) } \\
\hline 0 to 19,000 & $12(17.39)$ \\
\hline 20,000 to 39,000 & $21(30.43)$ \\
\hline 40,000 to 59,000 & $16(23.19)$ \\
\hline 60,000 and more & 20 (28.99) \\
\hline \multicolumn{2}{|l|}{ Marital status } \\
\hline Married/Common law spouse & $44(63.77)$ \\
\hline Separated/Divorced & $3(4.35)$ \\
\hline Single & $7(10.14)$ \\
\hline Widow & $15(21.74)$ \\
\hline \multicolumn{2}{|l|}{ Chronic conditions } \\
\hline $1-2$ & $10(14.49)$ \\
\hline $3-4$ & 18 (26.09) \\
\hline $5-6$ & $19(27.54)$ \\
\hline 7 or more & $22(31.88)$ \\
\hline \multicolumn{2}{|l|}{ Multimorbidity score } \\
\hline Less than 10 & $37(53.62)$ \\
\hline More than 10 & $32(46.38)$ \\
\hline \multicolumn{2}{|l|}{ Family physicians' consultation } \\
\hline 0 & $7(10.14)$ \\
\hline $1-2$ & $50(72.46)$ \\
\hline 3 or more & $12(17.39)$ \\
\hline \multicolumn{2}{|l|}{ Specialists' consultations } \\
\hline 0 & $31(44.93)$ \\
\hline $1-2$ & $26(37.68)$ \\
\hline 3 or more & $12(17.39)$ \\
\hline \multicolumn{2}{|l|}{ Pharmacists' consultation } \\
\hline 0 & $17(24.64)$ \\
\hline $1-2$ & $23(33.33)$ \\
\hline 3 or more & $29(42.03)$ \\
\hline \multicolumn{2}{|c|}{$\begin{array}{l}\text { Total number of healthcare professionals' } \\
\text { consultation }\end{array}$} \\
\hline 0 & $1(1.45)$ \\
\hline 1 to 5 & $20(28.99)$ \\
\hline 6 to 10 & 27 (39.13) \\
\hline 11 or more & $21(30.43)$ \\
\hline
\end{tabular}

\subsection{Association between HL and the number of health-} care professionals' consultations

Table 3 shows the variables associated with the total number of consultations with healthcare professionals, for both simple and multiple Poisson regressions. In the multiple Poisson regression model, a higher score in the HLQ dimension Appraisal of health information (IRR $=0.66, p=.027)$ and a higher number of chronic conditions (IRR $=1.11 ; p<.001)$ were associated with fewer consultations with healthcare professionals.

\section{Discussion}

First, our study revealed that the number of consultations with all healthcare professionals is almost three times greater than in a Canadian study, that investigated the use of all healthcare services amongst older adults (11.57 vs. 3.77, respectively). ${ }^{[21]}$ Those differences might be due to the high rate of chronic diseases found in our sample. Canadian older adults with at least three chronic conditions presented a rate of medical consultations up to three times higher than older adults without any chronic condition. It was further suggested that the use of healthcare services, especially in primary care settings increases with each additional diseases. ${ }^{\left[{ }^{8]}\right.}$ Having a large number of healthcare consultations does not necessarily have a negative impact, and it is impossible to consider all the visits reported as improper. Indeed, older adults living with chronic conditions are encouraged to use preventive services, such as community pharmacies and primary care to help meet their health needs. ${ }^{[22]}$ The development of HL and patient empowerment requires regular reinforcement. Therefore, most interventions aiming to improve HL involve two or more contacts with healthcare professionals. ${ }^{[23]}$ However, multiple healthcare visits among older adults do not guarantee HL improvement in this group. Their medical follow-up may not be optimal, as they do not meet the comprehension needs of older adults. ${ }^{[8]}$ However, the fact that we do not consider the purpose of the visit prevent us from drawing further conclusions.

Regarding HL, results suggest that the overall scores were relatively high in all subgroups. This is not in agreement with prior studies that have suggested that the large majority of older adults do not reach a level of HL high enough to manage their health conditions. ${ }^{[24]}$ However, studies reporting generalized low HL levels used different measurement tools. Despite being widely used in research, questionnaires assessing HL such as the Rapid Estimate of Adult Literacy in Medicine (REALM), the Test of Functional Health Literacy in Adults (TOFHLA) and the Newest Vital Sign (NVS) tend to evaluate only reading comprehension, and do not assess all aspects. ${ }^{[25]}$ Thus, the goal of the HLQ is to focus on the 
knowledge needs of individuals and organizations by evaluat- high, it is important to focus on the lower ones, which point ing various HL dimensions. Hence, even if our scores appear out important needs and intervention targets. ${ }^{[14]}$

Table 2. Description of health literacy

\begin{tabular}{|c|c|c|c|c|c|c|c|c|c|}
\hline \multirow[b]{2}{*}{ Variables } & \multicolumn{9}{|c|}{ Description of the HLQ's 9 dimensions, Mean \pm SD } \\
\hline & $\begin{array}{l}\text { 1. Feeling } \\
\text { understood and } \\
\text { supported by health } \\
\text { care professionals }\end{array}$ & $\begin{array}{l}\text { 2. Having } \\
\text { sufficient } \\
\text { information to } \\
\text { manage health }\end{array}$ & $\begin{array}{l}\text { 3. Actively } \\
\text { managing } \\
\text { my health }\end{array}$ & $\begin{array}{l}\text { 4. Social } \\
\text { support for } \\
\text { health }\end{array}$ & $\begin{array}{l}\text { 5. Appraisal } \\
\text { of health } \\
\text { information }\end{array}$ & $\begin{array}{l}\text { 6. Ability to } \\
\text { actively engage } \\
\text { with health care } \\
\text { professionals }\end{array}$ & $\begin{array}{l}\text { 7. Navigating } \\
\text { the healthcare } \\
\text { System }\end{array}$ & $\begin{array}{l}\text { 8. Ability to } \\
\text { find good } \\
\text { health } \\
\text { information }\end{array}$ & $\begin{array}{l}9 . \\
\text { Understanding } \\
\text { health } \\
\text { information }\end{array}$ \\
\hline \multicolumn{10}{|l|}{ Sex } \\
\hline Males & $3.34 \pm 0.68$ & $3.07 \pm 0.64$ & $3.03 \pm 0.55$ & $3.20 \pm 0.57$ & $2.90 \pm 0.61$ & $4.07 \pm 0.60$ & $3.84 \pm 0.70$ & $3.80 \pm 0.63$ & $3.96 \pm 0.72$ \\
\hline \multirow[t]{2}{*}{ Females } & $3.46 \pm 0.50$ & $3.22 \pm 0.48$ & $3.27 \pm 0.50$ & $3.22 \pm 0.47$ & $3.11 \pm 0.53$ & $3.98 \pm 0.79$ & $3.68 \pm 0.80$ & $3.87 \pm 0.74$ & $4.10 \pm 0.60$ \\
\hline & $p=\mathrm{NS}$ & $p=\mathrm{NS}$ & $p=\mathrm{NS}$ & $p=\mathrm{NS}$ & $p=\mathrm{NS}$ & $p=\mathrm{NS}$ & $p=\mathrm{NS}$ & $p=\mathrm{NS}$ & $p=\mathrm{NS}$ \\
\hline \multicolumn{10}{|l|}{ Age range } \\
\hline $65-69$ & $3.40 \pm 0.57$ & $3.05 \pm 0.52$ & $3.20 \pm 0.56$ & $3.16 \pm 0.46$ & $3.02 \pm 0.57$ & $3.97 \pm 0.67$ & $3.57 \pm 0.79$ & $3.77 \pm 0.77$ & $3.99 \pm 0.63$ \\
\hline $70-74$ & $3.42 \pm 0.54$ & $3.11 \pm 0.47$ & $2.98 \pm 0.33$ & $3.21 \pm 0.38$ & $2.87 \pm 0.54$ & $4.01 \pm 0.62$ & $3.77 \pm 0.75$ & $3.69 \pm 0.74$ & $4.10 \pm 0.71$ \\
\hline 75-79 & $3.30 \pm 0.91$ & $3.13 \pm 0.89$ & $3.16 \pm 0.82$ & $3.12 \pm 0.83$ & $3.18 \pm 0.88$ & $4.54 \pm 0.51$ & $4.37 \pm 0.52$ & $4.42 \pm 0.52$ & $4.42 \pm 0.56$ \\
\hline $80-84$ & $3.43 \pm 0.91$ & $3.43 \pm 0.37$ & $3.45 \pm 0.41$ & $3.42 \pm 0.48$ & $3.18 \pm 0.35$ & $3.71 \pm 1.04$ & $3.53 \pm 0.73$ & $3.75 \pm 0.49$ & $3.91 \pm 0.75$ \\
\hline \multirow[t]{2}{*}{85 or more } & $3.50 \pm 0.43$ & $3.25 \pm 0.29$ & $3.06 \pm 0.47$ & $3.38 \pm 0.45$ & $2.94 \pm 0.32$ & $3.97 \pm 0.48$ & $3.79 \pm 0.70$ & $3.77 \pm 0.39$ & $3.82 \pm 0.45$ \\
\hline & $p=\mathrm{NS}$ & $p=\mathrm{NS}$ & $p=\mathrm{NS}$ & $p=\mathrm{NS}$ & $p=\mathrm{NS}$ & $p=\mathrm{NS}$ & $p=\mathrm{NS}$ & $p=\mathrm{NS}$ & $p=\mathrm{NS}$ \\
\hline \multicolumn{10}{|l|}{ Marital status } \\
\hline Married & $3.46 \pm 0.57$ & $3.16 \pm 0.55$ & $3.19 \pm 0.56$ & $3.26 \pm 0.52$ & $3.02 \pm 0.56$ & $4.00 \pm 0.71$ & $3.75 \pm 0.73$ & $3.80 \pm 0.66$ & $4.00 \pm 0.64$ \\
\hline Separated & $2.58 \pm 0.83$ & $2.42 \pm 0.55$ & $2.47 \pm 0.42$ & $2.60 \pm 0.53$ & $2.13 \pm 0.12$ & $3.20 \pm 1.11$ & $2.78 \pm 1.11$ & $3.33 \pm 0.83$ & $3.87 \pm 0.99$ \\
\hline Single & $3.33 \pm 0.43$ & $2.42 \pm 0.38$ & $3.23 \pm 0.44$ & $3.24 \pm 0.43$ & $3.25 \pm 0.39$ & $4.16 \pm 0.58$ & $3.90 \pm 0.70$ & $4.07 \pm 0.53$ & $4.19 \pm 0.55$ \\
\hline \multirow[t]{2}{*}{ Widow } & $3.57 \pm 0.70$ & $3.29 \pm 0.57$ & $3.29 \pm 0.57$ & $3.29 \pm 0.56$ & $2.91 \pm 0.75$ & $4.14 \pm 0.58$ & $3.88 \pm 0.74$ & $3.77 \pm 1.07$ & $4.19 \pm 0.88$ \\
\hline & $p=\mathrm{NS}$ & $p=\mathrm{NS}$ & $p=\mathrm{NS}$ & $p=\mathrm{NS}$ & $p=\mathrm{NS}$ & $p=\mathrm{NS}$ & $p=\mathrm{NS}$ & $p=\mathrm{NS}$ & $p=\mathrm{NS}$ \\
\hline \multicolumn{10}{|l|}{ Education level } \\
\hline Primary & $3.31 \pm 0.53$ & $3.29 \pm 0.45$ & $3.07 \pm 0.36$ & $3.35 \pm 0.40$ & $3.08 \pm 0.45$ & $4.18 \pm 0.57$ & $3.95 \pm 0.70$ & $3.98 \pm 0.64$ & $4.05 \pm 0.60$ \\
\hline Secondary & $3.32 \pm 0.65$ & $3.00 \pm 0.63$ & $3.13 \pm 0.62$ & $3.08 \pm 0.61$ & $2.741 \pm 0.63$ & $3.81 \pm 0.85$ & $3.59 \pm 0.65$ & $3.62 \pm 0.63$ & $3.85 \pm 0.67$ \\
\hline Post-secondary & $3.39 \pm 0.64$ & $3.17 \pm 0.51$ & $3.03 \pm 0.56$ & $3.20 \pm 0.54$ & $3.12 \pm 0.49$ & $3.92 \pm 0.69$ & $3.53 \pm 0.92$ & $3.701 \pm 0.77$ & $4.03 \pm 0.71$ \\
\hline \multirow[t]{2}{*}{ University } & $3.73 \pm 0.31$ & $3.25 \pm 0.53$ & $3.55 \pm 0.38$ & $3.37 \pm 0.35$ & $3.30 \pm 0.55$ & $4.33 \pm 0.54$ & $4.11 \pm 0.62$ & $4.25 \pm 0.59$ & $4.47 \pm 0.45$ \\
\hline & $p=\mathrm{NS}$ & $p=\mathrm{NS}$ & $p=.024$ & $p=$ NS & $p=\mathrm{NS}$ & $p=\mathrm{NS}$ & $p=\mathrm{NS}$ & $p=.034$ & $p=\mathrm{NS}$ \\
\hline \multicolumn{10}{|l|}{ Income level } \\
\hline 0 to 19,000 & $2.92 \pm 0.95$ & $2.94 \pm 0.79$ & $2.38 \pm 0.75$ & $3.00 \pm 0.89$ & $2.77 \pm 0.86$ & $4.00 \pm 0.88$ & $3.67 \pm 0.93$ & $3.70 \pm 0.92$ & $3.97 \pm 0.80$ \\
\hline 20 to 39,000 & $3.46 \pm 0.42$ & $3.24 \pm 0.44$ & $3.30 \pm 0.42$ & $3.25 \pm 0.41$ & $3.06 \pm 0.51$ & $4.12 \pm 0.61$ & $3.78 \pm 0.74$ & $4.03 \pm 0.51$ & $4.12 \pm 0.59$ \\
\hline 40 to 59,000 & $3.48 \pm 0.36$ & $3.27 \pm 0.35$ & $3.14 \pm 0.47$ & $3.29 \pm 0.42$ & $2.95 \pm 0.43$ & $3.83 \pm 0.86$ & $3.63 \pm 0.62$ & $3.70 \pm 0.54$ & $3.80 \pm 0.66$ \\
\hline \multirow{2}{*}{60,000 and more } & $3.58 \pm 0.58$ & $3.13 \pm 0.58$ & $3.24 \pm 0.49$ & $3.30 \pm 0.35$ & $3.19 \pm 0.48$ & $4.08 \pm 0.58$ & $3.88 \pm 0.79$ & $3.83 \pm 0.81$ & $4.23 \pm 0.59$ \\
\hline & $p=\mathrm{NS}$ & $p=\mathrm{NS}$ & $p=\mathrm{NS}$ & $p=\mathrm{NS}$ & $p=\mathrm{NS}$ & $p=\mathrm{NS}$ & $p=\mathrm{NS}$ & $p=\mathrm{NS}$ & $p=\mathrm{NS}$ \\
\hline \multicolumn{10}{|l|}{ Chronic conditions } \\
\hline $1-2$ & $3.55 \pm 0.35$ & $3.08 \pm 0.41$ & $3.14 \pm 0.46$ & $3.22 \pm 0.48$ & $2.80 \pm 0.50$ & $4.00 \pm 0.19$ & $3.68 \pm 0.36$ & $3.52 \pm 0.54$ & $3.86 \pm 0.38$ \\
\hline $3-4$ & $3.42 \pm 0.61$ & $3.15 \pm 0.57$ & $3.19 \pm 0.47$ & $3.26 \pm 0.42$ & $3.03 \pm 0.54$ & $4.32 \pm 0.63$ & $3.91 \pm 0.91$ & $4.00 \pm 0.89$ & $4.33 \pm 0.75$ \\
\hline $5-6$ & $3.43 \pm 0.38$ & $3.26 \pm 0.38$ & $3.15 \pm 0.42$ & $3.36 \pm 0.39$ & $3.11 \pm 0.42$ & $3.91 \pm 0.60$ & $3.61 \pm 0.67$ & $3.84 \pm 0.42$ & $3.87 \pm 0.64$ \\
\hline \multirow[t]{2}{*}{7 or more } & $3.31 \pm 0.78$ & $3.11 \pm 0.69$ & $3.16 \pm 0.71$ & $3.10 \pm 0.66$ & $3.04 \pm 0.73$ & $3.88 \pm 0.94$ & $3.78 \pm 0.84$ & $3.85 \pm 0.75$ & $4.06 \pm 0.63$ \\
\hline & $p=\mathrm{NS}$ & $p=\mathrm{NS}$ & $p=\mathrm{NS}$ & $p=\mathrm{NS}$ & $p=\mathrm{NS}$ & $p=\mathrm{NS}$ & $p=\mathrm{NS}$ & $p=\mathrm{NS}$ & $p=.04$ \\
\hline Total average & $3.40 \pm 0.58$ & $3.16 \pm 0.54$ & $3.16 \pm 0.53$ & $3.22 \pm 0.51$ & $3.02 \pm 0.57$ & $4.02 \pm 0.71$ & $3.75 \pm 0.76$ & $3.84 \pm 0.69$ & $4.05 \pm 0.65$ \\
\hline
\end{tabular}

Table 3. Association with total healthcare professional consultations

\begin{tabular}{|c|c|c|c|c|}
\hline \multirow{2}{*}{ Variables } & \multicolumn{2}{|c|}{ Simple Poisson regression model } & \multicolumn{2}{|c|}{ Multiple Poisson regression model } \\
\hline & IRR (95\% CI) & p-value & IRR (95\% CI) & $p$-value \\
\hline 1. Feeling understood and supported by health care professionals & $1.20(1.67-1.36)$ & .006 & $1.18(0.88-1.60)$ & .270 \\
\hline 3. Actively managing my health & $1.15(1.00-1.31)$ & .047 & $1.40(0.95-2.01)$ & .089 \\
\hline 4. Social support for health & $1.11(0.96-1.27)$ & .165 & - & - \\
\hline 5. Appraisal of health information & $0.90(0.80-1.01)$ & .084 & $0.66(0.45-0.95)$ & .027 \\
\hline 6. Ability to actively engage with health care professionals & $0.97(0.88-1.07)$ & .555 & - & - \\
\hline 7. Navigating the Healthcare system & $1.03(0.94-1.13)$ & .481 & - & - \\
\hline 8. Ability to find good health information & $0.97(0.88-1.07)$ & .535 & - & - \\
\hline 9. Understanding health information & $1.07(0.96-1.19)$ & .210 & - & - \\
\hline Sex F (vs. M) & $1.06(0.92-1.22)$ & .393 & - & - \\
\hline Age & $1.01(1.00-1.02)$ & .070 & $1.01(1.00-1.03)$ & .357 \\
\hline Birthplace outside of Quebec (vs. in Quebec) & $1.82(1.40-2.36)$ & .000 & $1.23(0.70-2.15)$ & .476 \\
\hline \multicolumn{5}{|l|}{ Education level } \\
\hline Primary (reference category) & - & - & - & - \\
\hline Secondary & $1.14(0.83-1.58)$ & .43 & $0.88(0.60-1.28)$ & .50 \\
\hline Post-secondary & $1.53(1.11-2.109)$ & .01 & $1.38(0.974-1.96)$ & .07 \\
\hline University & $1.30(0.91-1.87)$ & .16 & $1.03(0.63-1.67)$ & .91 \\
\hline Income level less than $\mathbf{2 0 , 0 0 0}$ & $0.77(0.62-0.96)$ & .022 & $0.81(0.57-1.15)$ & .237 \\
\hline Chronic conditions & $1.25(1.22-1.28)$ & $<.001$ & $1.11(1.06-1.16)$ & $<.001$ \\
\hline
\end{tabular}

Note. CI: Confidence interval; Bold coefficients are included in the multivariable model 
Beauchamp et al. ${ }^{[26]}$ conducted research in order to measure HL, notably amongst people over 65 years of age. The general scores obtained for each dimension are similar to those found in this study. For dimensions 1 to 5, the highest score in both studies concerned Feeling understood and supported by healthcare providers dimension and the lowest score related to Appraisal of health information dimension. However, the highest and lowest scores for dimensions 6 to 9 were different between the two studies.

Our results further suggest that more educated people tend to have higher scores on the Actively managing my health and the Ability to find good health information dimensions. Education level is recognized by many as one of the principal elements influencing HL, by increasing general knowledge and self-management capacities. ${ }^{[27]}$ These results also brought to light that participants with more chronic conditions tend to score better on the Understand health information well enough to know what to do dimension. This is in conflict with the results of many previous studies which reported that people with a greater number of chronic conditions are more likely to have a lower HL as well as a lower physical autonomy. ${ }^{[28]}$ However, people with more chronic conditions are more often exposed to healthcare professional education, which could lead them to develop greater abilities in some HL fields. ${ }^{[29]}$

The results from the regression models indicated that the Appraisal of health information dimension is associated with the total number of consultations with healthcare professionals. Specifically, people with a weaker appraisal of health information tend to consult healthcare professionals more often. People performing poorly in that domain are subject to difficulties in understanding and applying health information. This result is in line with other studies suggesting that people with limited comprehension of health information tend to perform poorly on many spheres such as general health status, use of preventive healthcare services and chronic disease management. ${ }^{[27,30]}$ Previous research also reported an association between HL and the use of healthcare services, the services studied were mainly hospitalization, emergency services use and family physician follow-up. Indeed, people with a better understanding of health information use fewer healthcare services, such as emergency services, because the adequate management of their own health tends to limit the number of complications they experience due to their illness. ${ }^{[30,31]}$

Additionally, the fact that all participants had a family physician may have impacted the number of healthcare professionals consulted. Having a family physician may increase the use of preventive and specialized healthcare services such as medical specialists, because of easier access to referrals. ${ }^{[32]}$ Finally, the present study showed a positive association between the number of consultations with healthcare professionals and the number of chronic diseases. This result is in line with previous studies maintaining that the number of health conditions is associated with a higher use of healthcare services. ${ }^{[8]}$ Also, the accumulation of chronic health conditions puts older adults in a situation of vulnerability regarding their health, increasing their use of healthcare services to handle the multiple symptoms related to their diseases. ${ }^{[33]}$

The associations found between specific dimensions of HL and use of healthcare services have the potential to be beneficial in practice. Healthcare professionals would benefit from being aware of their patients overall HL. Further sensitization and training could help them support knowledge acquisition and comprehension amongst older adults. ${ }^{[34]}$ Nurses are especially concerned, being often at the core of patient education and disease management interventions. For older adults, the information that needs to be understood during a healthcare visit is important and their understanding barriers can lead to a reduced autonomy, amongst others. ${ }^{[25]}$ In this context, enabling older adults to use, understand and access health information can be a challenge for healthcare professionals. HL can be improved through several ways, including assessment methods, systematic interventions and structured patient education. ${ }^{[2]} \mathrm{HL}$ assessment in clinical settings could help healthcare professionals identify patients needing additional support. However, the process may be difficult, as many established instruments are not adapted for use in a demanding clinical setting. ${ }^{[35]}$ Also, other authors support that HL screening in clinical settings should be avoided, as it could cause stigmatization and a deterioration of the therapeutic relation. ${ }^{[36]}$ Systematic interventions are an easily integrable option to daily professional practice: organization of information to facilitate understanding, maintaining patient interaction throughout the conversation and communicating in a clear and simple style. ${ }^{[34]}$ Brooks et al. ${ }^{[2]}$ also point out the importance of trust and relationship building to attain effective communication. Finally, promoting partnership-building, collaboration and behaviour change implies improved skills for healthcare professionals. ${ }^{[37]}$ Specifically, nurses that are aware of the HL concept are more empowered to provide effective patient education. ${ }^{[38]}$

Finally, older adults that are better able to take care of their health would be less likely to make emergency department visits deemed preventable. ${ }^{[9]}$ Older adults visiting the emergency departments are particularly prone to adverse effects such as hospitalizations, functional decline, complications related to treatment and procedures and suboptimal followup. $^{[39,40]}$ 


\section{Limitations}

There are some limitations in our study. First, the use of self-report instruments may have lowered the reliability of the present results, notably by introducing a memory bias, especially when reporting the use of healthcare services. However, the targeted 6-month period may have allowed participants to remember the information more easily than a 12-month period. The size of the present sample could also bring limitations, because it reduces the statistical power of our statistical analysis. Furthermore, the study focused on the number of visits without considering their purposes, which limited the conclusions drawn regarding healthcare service use. However, the portrait of HL can still be considered pertinent and comparable to previous results in the literature.

The characteristics of the present study sample do not allow for a generalization of the results to the entire study population; i.e., the community-dwelling older adults with at least one chronic condition. However, the results are relevant to the population of older adults with a higher socioeconomic status who present multimorbidity issues, which is a group that has been studied very little.

\section{Conclusion}

This study mainly reported that people with poor Appraisal of health information tended to report a greater number of healthcare professional consultations, even if we cannot assess if all of the consultations were accurate. Overall, our results have the potential to be beneficial in practice and at the health policies level. Despite the limitations of this study, it demonstrates that taking account of the HL dimensions allows an optimization of the patients' health outcomes. This research brings forward additional information to understand the use of different healthcare services and HL amongst older adults living in a remote area. However, more research needs to be conducted on the use of all types of healthcare services in relation to the older adults' HL. This could help optimize patients follow up and guide them toward appropriate services.

\section{ACKNOWLEDGEMENTS}

The authors would like to thank all the healthcare professionals who graciously offered their help in recruiting participants.

\section{CONFliCtS OF INTEREST Disclosure}

The authors declare they have no conflicts of interest.

\section{REFERENCES}

[1] Kirk J, Grzywacz JG, Arcury TA, et al. Performance of health literacy tests among older adults with diabetes. Journal of General Internal Medicine. 2012; 27(5): 534-40. PMid:22095571 https: //doi.org/10.1007/s11606-011-1927-y

[2] Brooks C, Ballinger C, Nutbeam D, et al. The importance of building trust and tailoring interactions when meeting older adults' health literacy needs. Disability and Rehabilitation: An International, Multidisciplinary Journal. 2017; 39(23): 2428-35. PMid:27712121. https://doi.org/10.1080/09638288.2016.1231849

[3] Conseil canadien sur l'apprentissage. Littératie en santé au Canada: Résultats initiaux de l'Enquête internationale sur l'alphabétisation et les compétences des adultes. 2007 [cited 2018 September 15]. Available from: https://central.bac-lac.gc.ca/.item?i d=litteratie_en_sante\&op=pdf\&app=Library

[4] Sorensen K, Van den Broucke S, Fullam J, et al. Health literacy and public health: A systematic review and integration of definitions and models. BMC Public Health. 2012; 12: 80-93. PMid:22276600. https://doi.org/10.1186/1471-2458-12-80

[5] Findley A. Low Health Literacy and Older Adults: Meanings, Problems, and Recommendations for Social Work. Social Work in Health Care. 2015; 54(1): 65-81. PMid:25588097. https://doi .org/10 $.1080 / 00981389.2014 .966882$

[6] Geboers B, de Winter A, Spoorenberg S, et al. The association between health literacy and self-management abilities in adults aged 75 and older, and its moderators. Quality of Life Research. 2016; 25(11): 45-53. PMid:27101999. https://doi.org/10.1007/s1 1136-016-1298-2

Published by Sciedu Press
[7] Berkman ND, Sheridan SL, Donahue KE, et al. Low health literacy and health outcomes: an updated systematic review. Annals Of Internal Medicine. 2011; 155(2): 97-107. PMid:21768583. https : //doi.org/10.7326/0003-4819-155-2-201107190-00005

[8] Institut canadien d'information sur la santé. Les personnes âgées et le système de santé: Quelles sont les répercussions des multiples affections chroniques. 2011 [Cited 2018 September 15]. Available from: https://secure.cihi.ca/free_products/air-chron ic_disease_aib_fr.pdf

[9] Herndon JB, Chaney M, Carden D. Health Literacy and Emergency Department Outcomes: A systematic Review. Annals of Emergency Medicine. 2011; 57(4): 334-345. PMid:21035902. https: //doi.org/10.1016/j.annemergmed.2010.08.035

[10] Cafiero M. Nurse practitioners' knowledge, experience, and intention to use health literacy strategies in clinical practice. Journal of Health Communication. 2013; 18: 70-81. PMid:24093347. https://doi.org/10.1080/10810730.2013.825665

[11] Cho YI, Lee SD, Arozullah AM, et al. Effects of health literacy on health status and health service utilization amongst the elderly. Social Science \& Medicine. 2008; 66(8): 1809-1816. PMid:18295949. https://doi.org/10.1016/j.socscimed .2008.01.003

[12] Wilson NW, Couper ID, De Vries E, et al. A critical review of interventions to redress the inequitable distribution of healthcare professionals to rural and remote areas. Rural and Remote Health. 2009; 9(2): 1060-1060. PMid:19530891.

[13] Burns N, Grove SK. The practice of nursing research: appraisal, synthesis, and generation of evidence. 6th ed. St-Louis, MR: Saunders Elsevier; 2009. 
[14] Osborne RH, Batterham RW, Elsworth GR, et al. The grounded psychometric development and initial validation of the Health Literacy Questionnaire (HLQ). BMC Public Health. 2013; 13: 658-658. PMid:23855504. https ://doi.org/10.1186/1471-2 458-13-658

[15] De Jordy LC. Traduction et validation française canadienne du questionnaire de la littératie en santé (QLS). Master's thesis. Université du Québec à Chicoutimi, Saguenay, Quebec (Canada); 2018.

[16] Statistique Canada. Enquête nationale sur la santé de la population : Volet ménages. 2000 [Cited 2018 September 15]. Available from:http://www23.statcan.gc.ca/imdb/p2SV_f.pl?F unction=getSurvey\&SDDS=3225

[17] Poitras ME, Fortin M, Hudon C, et al. Validation of the disease burden morbidity assessment by self-report in a French-speaking population. BMC Health Services Research. 2012; 12: 35. PMid:22333434. https://doi.org/10.1186/1472-6963-12-35

[18] Hudon C, Chouinard MC, Couture M, et al. Partners for the optimal organisation of the healthcare continuum for high users of health and social services: protocol of a developmental evaluation case study design. BMJ Open. 2014; 4(12): e006991. PMid:25468510. https://doi.org/10.1136/bmjopen-2014-006991

[19] Plichta Kellar S, Kelvin EA. Munro's Statistical Methods for health Care Research. 6th ed. Philadelphia, PA: Lippincott Williams \& Wilkins; 2013.

[20] Chatterjee S, Simonoff J. Handbook of regression analysis. Hoboken: N.J.: John Wiley \& Sons, Inc; 2013.

[21] Institut de la Statistique du Québec. Enquête québécoise sur les limitations d'activités, les maladies chroniques et le vieillissement 2010-2011: Utilisation des services de santé et des services sociaux par les personnes de 65 ans et plus. 2013 [Cited 2018 September 15]. Available from: http://www.stat.gouv.qc.ca/statisti ques/sante/services/incapacites/limitations-malad ies-chroniques-utilisation.html

[22] National Center for Chronic Disease Prevention and Health Promotion. The state of aging and health in America 2013. US Department of Health and Human Services. 2013 [Cited 2018 September 15]. Available from: https://www.cdc.gov/aging/pdf/stat e-aging-health-in-america-2013.pdf

[23] Brainard J, Yoon L, Salter C, et al. Healthy ageing in Europe: prioritizing interventions to improve health literacy. BMC Research Notes. 2016; 9: 1-11. PMid:27176006. https://doi.org/10.1186/s1 3104-016-2056-9

[24] Conseil canadien sur l'apprentissage. L'Enquête de 2008 sur l'attitude des Canadien à l'égard de l'apprentissage : Résultats pour l'apprentissage tout au long de la vie. 2008 [Cited 2018 September 15]. Available from : https://www12.statcan.gc.ca/census -recensement/2006/consultation/92-135/surveys-enque tes/canada-attitude-canadiens-fra.cfm

[25] Association canadienne de santé publique. Exemple de mise en application de la littératie en santé. 2014 [Cited 2018 September 15]. Available from: https: //www.reseaudumieuxetre.ca/publications/exemples-d e-mise-en-application-de-la-litteratie-en-sante/

[26] Beauchamp A, Buchbinder R, Dodson S, et al. Distribution of health literacy strengths and weaknesses across socio-demographic groups: a cross-sectional survey using the Health Literacy Questionnaire (HLQ). BMC Public Health. 2015; 15: 678. PMid:26194350. https ://doi.org/10.1186/s12889-015-2056-z

[27] Ownby RL, Waldrop-Valverde D, Taha J. Why is health literacy related to health? An exploration among U.S. national assessment of adult literacy participants 40 years of age and older. Educational
Gerontology. 2012; 38(11): 776-787. https ://doi.org/10.108 $0 / 03601277.2011 .645441$

[28] Abolfathi Momtaz Y, Ibrahim R, Hamid TA. The impact of giving support to others on older adults' perceived health status. Psychogeriatrics. 2014; 14(1): 31-37. PMid:24299124. https ://doi .org/10 $.1111 /$ psyg. 12036

[29] Ullrich A, Schöpf AC, Nagl M, et al. 'Active in rehab': Development and formative evaluation of a patient education program to increase health literacy of patients with chronic illness. Rehabilitation. 2015; 54(2): 109-115. PMid:25719995. https://doi.org/ $10.1055 / \mathrm{s}-0034-1394450$

[30] Edwards M, Wood F, Davies M, et al. The development of health literacy in patients with a long-term health condition: Health literacy pathway model. BMC Public Health. 2012; 12: 130. PMid:22332990. https : //doi.org/10.1186/1471-2458-12-130

[31] Conseil canadien sur l'apprentissage. Littératie en santé au Canada: Une question de bien-être. 2008 [Cited 2018 September 15]. Available from: http://www.bdaa.ca/biblio/recherche/cca/s ante/sante.pdf

[32] Agence de la santé et des services sociaux du Saguenay-Lac-St-Jean. Enquête de santé du Saguenay-Lac-St-Jean 2012: Rapport sommaire. Saguenay, QC: ASSS-SLSJ; 2013.

[33] Quinlan P, Price KO, Magid SK, et al. The relationship among health literacy, health knowledge, and adherence to treatment in patients with rheumatoid arthritis. HSS Journal: The Musculoskeletal Journal of Hospital for Special Surgery. 2013; 9(1): 42-9. PMid:24426844. https://doi.org/10.1007/s11420-012-9308-6

[34] Le Collège des médecins de famille du Canada. Conseil pratique: Littératie en santé dans le Centre de médecine de famille. Le Collède des médecins de famille du Canada. 2016 [Cited 2018 September 15]. Available from: http://patientsmedicalhome.ca/fr/resour ces/conseils-pratiques/conseil-pratique-litterati e-en-sante-dans-le-centre-de-medecine-de-famille

[35] Goodman MS, Griffey RT, Carpenter CR, et al. Do Subjective Measures Improve the Ability to identify Limited Health Litaracy in Clinical Setting? American Journal of Managed Care. 2014; 28(5): 584-94. PMid:26355130. https://doi .org/10.3122/jabfm. 20 15.05.150037

[36] Agence de la santé et des services sociaux de Montréal. Pour qu'on se comprenne: Guide de littératie en santé: Direction de la santé publique. 2014 [Cited 2018 September 15]. Available from: http://www.santecom.qc.ca/bibliothequevirtuel le/Montreal/9782896733231.pdf

[37] MacLeod S, et al. The impact of inadequate health literacy on patient satisfaction, healthcare utilization, and expenditures among older adults. Geriatric Nursing. 2017; 38(4): 334-341. PMid:28089217. https ://doi.org/10.1016/j.gerinurse.2016.12.003

[38] Chan A. Heath literacy screening instruments in adults with cardiovascular disease and their importance to the nursing profession. Australian Journal of Advanced Nursing. 2014; 32(2): 14-23.

[39] Calder L, Pozgay A, Riff S, et al. Adverse events in patients with return emergency department visits. BMJ Quality \& Safety. 2015; 24(2): 142-148. PMid:25540424. https ://doi.org/10.1136/bm jqs-2014-003194

[40] Carpenter CR, Shelton E, Fowler S, et al. Risk factors and screening instruments to predict adverse outcomes for undifferentiated older emergency department patients: a systematic review and metaanalysis. Academic Emergency Medicine: Official Journal Of The Society For Academic Emergency Medicine. 2015; 22(1): 1-21. PMid:25565487. https://doi.org/10.1111/acem.12569 